\title{
Correction to: Medical device legislation for custom-made devices after the UK has left the EU: answers to ten important questions
}

The original article can be found online at https://doi.org/10.1038/s41415-021-3530-x

Journal's correction note:

General article Br Dent J 2021; 231: 513-521.

When this article was initially published, the ticks in Table 2 were not visible in the online version. The correct table is presented here.

Table 2 Aspects of the General Dental Council Scope of practice that can pertain to custom-made devices, indicating which of its registrants may undertake which procedures, if trained, competent and indemnified

\begin{tabular}{|c|c|c|c|c|c|c|c|}
\hline Procedure & $\begin{array}{l}\text { Dental } \\
\text { nurses }\end{array}$ & $\begin{array}{l}\text { Orthodontic } \\
\text { therapists }\end{array}$ & $\begin{array}{l}\text { Dental } \\
\text { hygienists }\end{array}$ & $\begin{array}{l}\text { Dental } \\
\text { therapists }\end{array}$ & $\begin{array}{l}\text { Dental } \\
\text { technicians }\end{array}$ & $\begin{array}{l}\text { Clinical dental } \\
\text { technicians }\end{array}$ & Dentists \\
\hline $\begin{array}{l}\text { Perform technical and clinical procedures related to providing } \\
\text { removable dental appliances }\end{array}$ & & & & & & G & $\checkmark$ \\
\hline $\begin{array}{l}\text { Work with the dentist or clinical dental technician on treatment } \\
\text { planning and outline design }\end{array}$ & & & & & $\checkmark$ & $\checkmark$ & $\checkmark$ \\
\hline $\begin{array}{l}\text { Design, plan and make a range of custom-made dental devices } \\
\text { according to a prescription }\end{array}$ & & & & & $\checkmark$ & $\checkmark$ & $\checkmark$ \\
\hline Take impressions & A & D & $\checkmark$ & $\checkmark$ & $\mathrm{F}$ & G & $\checkmark$ \\
\hline Carry out intraoral scanning for CAD/CAM & & & & & $\mathrm{F}$ & G & $\checkmark$ \\
\hline $\begin{array}{l}\text { Take and process radiographs and other images related to providing } \\
\text { removable dental appliances }\end{array}$ & & & & & & G & $\checkmark$ \\
\hline Take occlusal registrations & & D & & & $\mathrm{F}$ & G & $\checkmark$ \\
\hline Take orthognathic facebow readings & & D & & & E & $\mathrm{F}$ & $\checkmark$ \\
\hline Carry out shade taking & B & & & & $\checkmark$ & $\checkmark$ & $\checkmark$ \\
\hline Pour, cast and trim study models & B & D & & & $\checkmark$ & $\checkmark$ & $\checkmark$ \\
\hline Prescribe and provide fixed orthodontic treatment & & & & & & & $\checkmark$ \\
\hline Prescribe and provide fixed and removable prostheses & & & & & & & $\checkmark$ \\
\hline Prescribe and provide complete dentures direct to patients & & & & & & $\checkmark$ & $\checkmark$ \\
\hline Prescribe and provide crowns and bridges & & & & & & & $\checkmark$ \\
\hline Construct occlusal registration rims and special trays & C & & & & $\checkmark$ & $\checkmark$ & $\checkmark$ \\
\hline Construct vacuum-formed retainers to the prescription of a dentist & C & & & & $\checkmark$ & $\checkmark$ & $\checkmark$ \\
\hline Construct mouthguards to the prescription of a dentist & C & & & & $\checkmark$ & $\checkmark$ & $\checkmark$ \\
\hline Provide sports mouthguards & & & & & & $\checkmark$ & $\checkmark$ \\
\hline Provide anti-snoring devices on prescription of a dentist & & & & & & H & $\checkmark$ \\
\hline Provide and fit other dental devices on prescription of a dentist & & & & & & $\checkmark$ & $\checkmark$ \\
\hline $\begin{array}{l}\text { Modify dental devices including dentures, orthodontic appliances, } \\
\text { crowns and bridges according to a prescription }\end{array}$ & & & & & $\checkmark$ & $\checkmark$ & $\checkmark$ \\
\hline Fit removable appliances & & & & & & G & $\checkmark$ \\
\hline Insert passive removable orthodontic appliances & & D & & & & D & $\checkmark$ \\
\hline Insert removable appliances activated or adjusted by a dentist & & D & & & & D & $\checkmark$ \\
\hline Fit bonded retainers & & D & & & & & $\checkmark$ \\
\hline Make a patient's orthodontic appliance safe in the absence of a dentist & & D & & & & & N/A \\
\hline Re-cement crowns with temporary cement & & & $\checkmark$ & $\checkmark$ & & H & $\checkmark$ \\
\hline Replace implant abutments for removable dental appliances & & & & & & H & $\checkmark$ \\
\hline Remove fixed appliances & & D & & & & & $\checkmark$ \\
\hline Repair dentures direct to patients & & & & & $\checkmark$ & $\checkmark$ & $\checkmark$ \\
\hline Repair the acrylic component of removable appliances & C & & & & $\checkmark$ & $\checkmark$ & $\checkmark$ \\
\hline Repair the acrylic component part of orthodontic appliances & & E & & & $\checkmark$ & $\checkmark$ & $\checkmark$ \\
\hline \multicolumn{8}{|c|}{$\begin{array}{l}\text { Key: } \\
A=\text { an additional skill that dental nurses could develop, carried out to the prescription of, or under the direction of, a dentist or a clinical dental technician (where appropriate). } \\
B=\text { additional skills that dental nurses could develop. } \\
C=\text { additional skills carried out on prescription from, or under the direction of, another registrant. } \\
D=\text { under prescription from a dentist. } \\
E=\text { an additional skill that orthodontic therapists could develop. } \\
F=\text { addditional skills that dental technicians could develop, working with a dentist or a clinical dental technician in the clinic, assisting with treatment. } \\
G=\text { under prescription from a dentist, unless for complete dentures. } \\
H=\text { an additional skill that clinical dental technicians could develop. }\end{array}$} \\
\hline
\end{tabular}

The journal apologises for any inconvenience caused. 